\title{
DO YOU THINK DCPS SHOULD HAVE DIRECT ACCESS?
}

The General Dental Council (GDC) is

considering allowing 'direct access' for

patients to members of the dental team other

than dentists and wants to hear views on

the subject.

At the moment, both the Standards

guidance and Scope of practice make it

clear that every member of the dental team

must work on the prescription of a dentist.

The only exception to this is with clinical dental technicians, who are able to provide full dentures to patients who have no teeth without the need for a prescription.

The GDC is now considering whether to remove this requirement and to allow 'direct access' for all patients. This would mean that patients could see other members of the dental team without seeing a dentist first, for example a dental hygienist or therapist.

A Task and Finish Group will ensure that any decision made is based on robust evidence. The Task and Finish Group wants to hear from as many stakeholders as possible and a short 'call for ideas' questionnaire has been published on the GDC's website www. gdc-uk.org.

The results from this call for ideas will be analysed and considered by the Direct Access Task and Finish Group at a meeting on 2 July 2012.

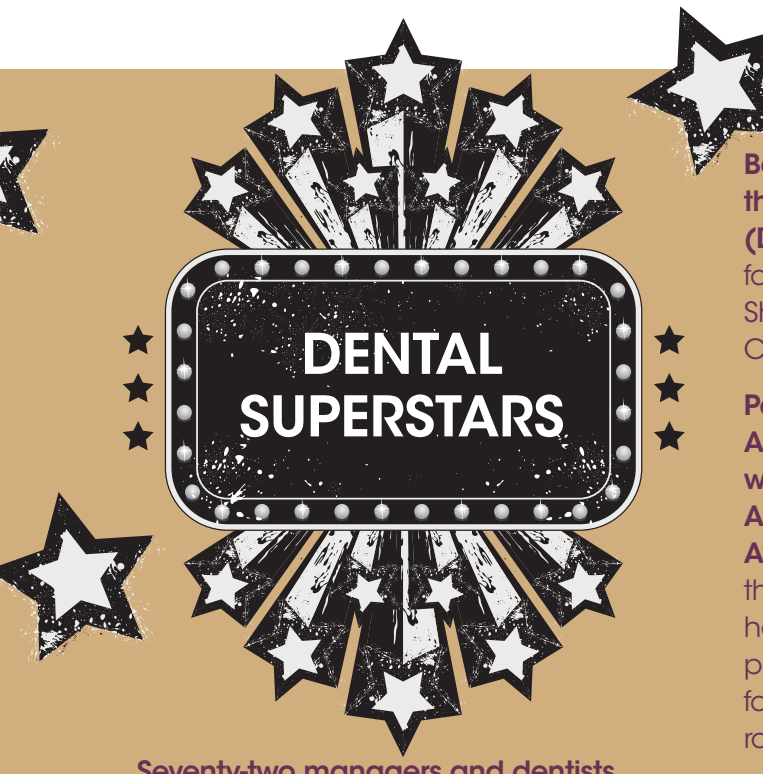

Seventy-two managers and dentists achieved an Institute of Leadership and Management qualification with UMD Professional in $2011 / 12$, the highest number to date. Twenty-three of the successful candidates were presented with their certificates a

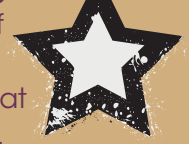

Successful graduates of UMD Professional's Institute of Leadership and Management qualification with John Tiernan of Dental Protection (front centre left) and Fiona StuartWilson of UMD Professional (front centre right) an awards reception in London.

Barry Appleby is the new President of the Dental Technologists Association (DTA). Barry has been a dental technician for over 35 years and is based in Telford, Shropshire, where he has owned and run a Commercial Laboratory since 1988.

Pam Swain, Chief Executive of the British Association of Dental Nurses (BADN), was presented with the Outstanding Achievement Award at the Dental Awards 2012 in April. Pam has worked fo the BADN for 20 years this summer and has been instrumental in both raising the profile of and obtaining professional status for dental nurses in recognition of their vital role in the dental team.

James Hull Associates held a gala dinner and the JHA awards at their clinical conference 2012. Best Practice of the Year went to Elgin; Practice Manager of the Year was Claire Mitchell; Receptionist/ Coordinator of the Year was Carolyn Hayes; Gemma Tomkinson was named Dental Nurse of the Year; Hygienist/Therapist of the Year went to Hilary Brown; and Rhys Jones and Daniel Peart were named Best Support Employees of the Year.
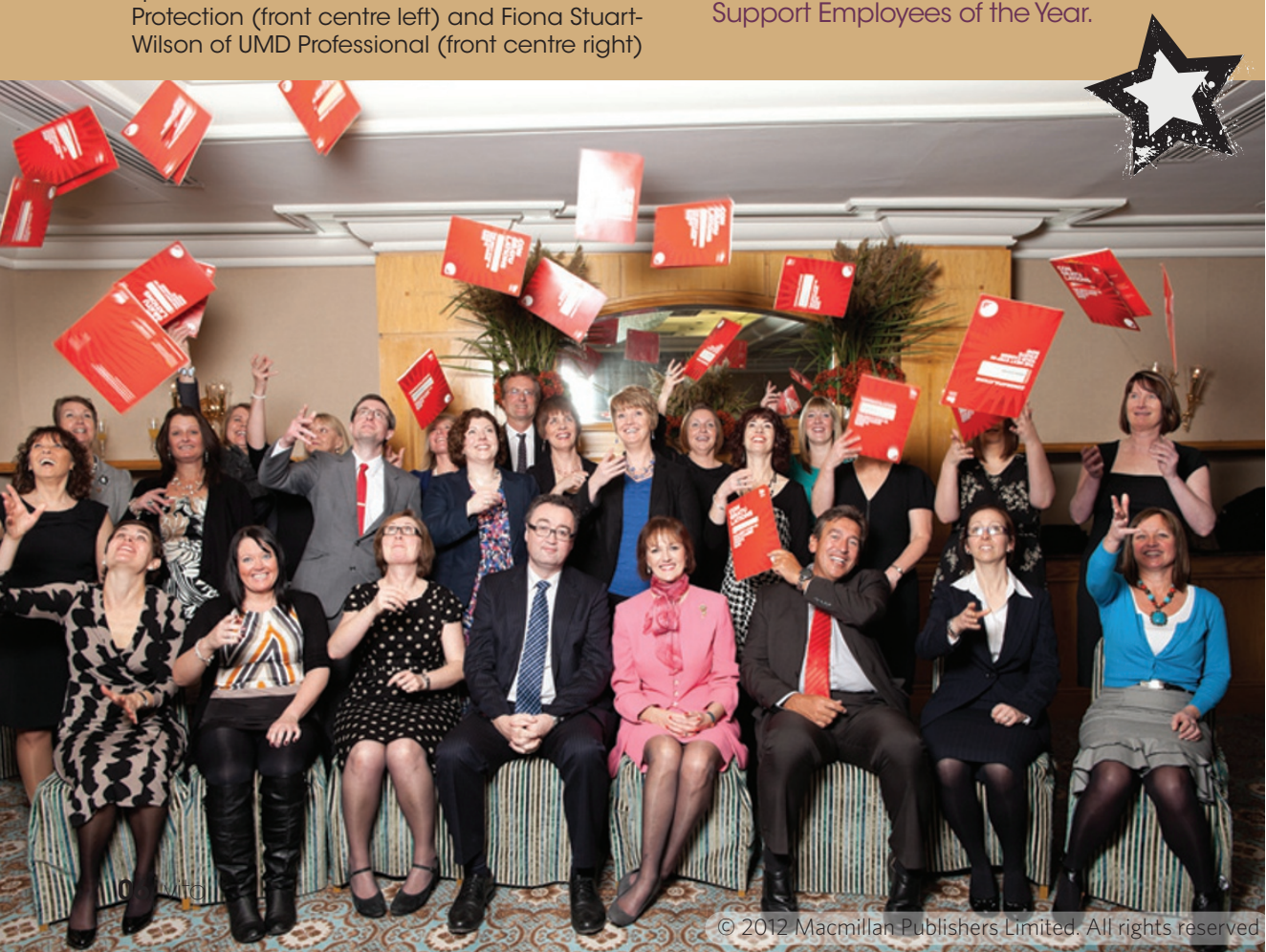

\section{BSDHT ANNOUNCES POSTER COMPETITION}

Sally Simpson, President of the British

Society of Dental Hygiene and Therapy

(BSDHT), has announced that this year's

Oral Health Conference \& Exhibition

will again include a Poster Competition

sponsored by Waterpik.

'Many individuals have, as part of their employment or continuing education, undertaken or been involved in research activity, which will be of great interest to others in the profession, said Sally. 'The competition isn't restricted to only those who have undertaken research - after all, not everyone will have been involved in research activity - but they may have a particular case they'd like to share with colleagues, or perhaps they'd like the opportunity to present a literature review.'

Sally hopes to encourage hygienists and hygienist-therapists to become active in exploring aspects of their work or related areas, and to submit their entries to this competition - entries which could ultimately be published in Dental Health.

During the Trade Exhibition at this year's Conference - being held for the first time at the Arena and Convention Centre Liverpool (ACC) - there will be space available to display posters summarising individual or group research.

The poster which is deemed to be the best in the group will be awarded a prize of registration for the BSDHT Oral Health Conference \& Exhibition on 9-10

November 2012.

For further details visit www.bsdht.org.uk.

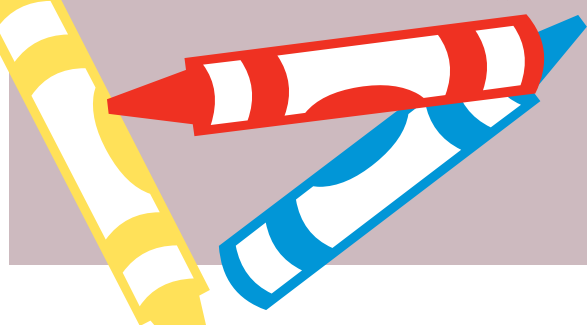

